\title{
Characterization of Wheat-Triticale Lines Resistant to Powdery Mildew, Stem Rust, Stripe Rust, Wheat Curl Mite, and Limitation on Spread of WSMV
}

\author{
Hongjie Li, The National Key Facility for Crop Gene Resources and Genetic Improvement (NFCRI), Institute of \\ Crop Science, Chinese Academy of Agricultural Sciences (CAAS), Beijing 100081, China; R. L. Conner, Agricul- \\ ture and Agri-Food Canada, Morden Research Station, Unit 100-101 Route 100, Morden, MB, R6M 1Y5, Canada; \\ Zhiyong Liu, Department of Plant Genetics and Breeding, China Agricultural University, Beijing 100094, China; \\ Yiwen Li and Yu Chen, The State Key Laboratory of Plant Cell and Chromosome Engineering, Institute of Genetics \\ and Developmental Biology, Chinese Academy of Sciences (CAS), Beijing 100101, China; Yilin Zhou and \\ Xiayu Duan, Key Laboratory for Biology of Plant Diseases and Insect Pests, Institute of Plant Protection, CAAS, \\ Beijing 100094, China; Tianmin Shen, Lankao Nonghua Seed Company, Lankao 730070, Henan Province, China; \\ Qin Chen and R. J. Graf, Agriculture and Agri-Food Canada, Lethbridge Research Centre, P. O. Box 3000, \\ Lethbridge, AB, T1J 4B1, Canada; and Xu Jia, The State Key Laboratory of Plant Cell and Chromosome Engineer- \\ ing, Institute of Genetics and Developmental Biology, CAS, Beijing 100101, China
}

\begin{abstract}
Li, H. J., Conner, R. L., Liu, Z. Y., Li, Y. W., Chen, Y., Zhou, Y. L., Duan, X. Y., Shen, T. M., Chen, Q., Graf, R. J., and Jia, X. 2007. Characterization of wheat-triticale lines resistant to powdery mildew, stem rust, stripe rust, wheat curl mite, and limitation on spread of WSMV. Plant Dis. 91:368-374.

High yield potential and the wide adaptability of wheat-rye T1BL·1RS translocation lines are attractive to breeders. The wheat-rye lines Lankao 1, 3, 4, and 5 were resistant to a wide spectrum of wheat powdery mildew (Blumeria graminis $\mathrm{f}$. sp. tritici) isolates from both China and Canada. They also were resistant to a mixture of wheat stem rust (Puccinia graminis f. sp. tritici) pathotypes (98WSR) and wheat stripe rust (P. striiformis f. sp. tritici) races from western Canada and China. Colonization of wheat curl mite (WCM) (Aceria tosichella) resulted in slower development of rolling and trapping leaves in the Lankao lines than in the WCM-susceptible check cultivars. The delayed development of Wheat streak mosaic (WSM) symptoms on Lankao lines was observed when transmitted by viruliferous WCM, even though they were susceptible to Wheat streak mosaic virus (WSMV). This effect of Lankao lines on limiting the spread of WSM was comparable with other known sources of WCM resistance. Sequential C-banding and genomic in situ hybridization analyses revealed the presence of a pair of T1BL-1RS translocated chromosomes in the Lankao lines. Segregation analysis of the $F_{2}$ progeny plants derived from crosses between Lankao 4 and the susceptible wheat cvs. Mingxian 169 and Lovrin 13 indicated that a single dominant gene was responsible for the isolate-specific resistance against wheat powdery mildew in Lankao 4. Polymerase chain reaction analysis using an STS marker amplified rye chromatin in powdery mildew-resistant and -susceptible $\mathrm{F}_{2}$ plants of the Mingxian $169 \times$ Lankao 4 cross demonstrated that the resistance of Lankao 4 was not controlled by a gene or genes located on the rye chromosome arm of T1BL.1RS. The resistance of the Lankao lines to diseases and limitation of the spread of WSMV, in combination with good quality and high yield potential, makes them useful for wheat improvement and production.
\end{abstract}

Additional keywords: Secale cereale, triticale, Triticum aestivum

Wheat (Triticum aestivum L. em. Thell.) is one of the major food crops in the world. It is estimated that the global consumption of wheat annually increases by 1.3 to $2.6 \%$ $(3,27)$. The improvement of grain yield is the most desirable way to meet the increasing demand for wheat, because there is limited capacity for expanding wheat acre-

Corresponding author: X. Jia or H. J. Li

E-mail: xjia@genetics.ac.cn

or hongjie@caas.net.cn

Accepted for publication 27 September 2006.

doi:10.1094/PDIS-91-4-0368

(C) 2007 The American Phytopathological Society
In China, T1BL·1RS translocation frequently is used in cultivar development since it was introduced in the 1970s $(13,40)$. This translocation chromosome is particularly attractive to breeders because it improves wheat yield potential $(33,34)$ and adaptation to various environments (26). The T1BL·1RS translocated chromosome that was derived from Petkus rye carries genes for race-specific resistance to wheat diseases, such as powdery mildew (Blumeria graminis (DC.) E. O. Speer $\mathrm{f}$. sp. tritici em. Marchal), stem rust (Puccinia graminis Pers.:Pers. f. sp. tritici Eriks. \& E. Henn.), stripe rust (P. striiformis Westend. f. sp. tritici Eriks.), and leaf rust ( $P$. triticina Eriks.) (21). Chromosome $1 \mathrm{R}$ of Insave rye is associated with resistance to the wheat curl mite (WCM) (Aceria tosichella Keifer), the vector of the devastating virus Wheat streak mosaic virus (WSMV) (10).

Although widely used in a great number of wheat cultivars, most of the T1BL·1RS chromosome translocations used in breeding programs are derived from only a few sources of rye (25). Over reliance on this translocation has made cultivars vulnerable to disease epidemics. Virulent pathogenic isolates of wheat powdery mildew, the rusts, and WCM biotypes have been identified that can overcome resistance to the diseases $(1,41)$ and WCM colonization (12) conferred by genes on the short chromosome arm 1RS. The circumvention of resistance by virulent races or pathotypes has caused significant losses in wheat production across various regions. Additionally, the T1BL·1RS translocation has been associated with inferior bread-making quality (9), which excludes it from further utilization in developing commercial cultivars. Wheat lines with this translocation may not be advanced in some breeding programs because of their poor quality $(17,33)$. The reason for the adverse effect on quality is the presence of locus Sec-1, which is located on 1RS and encodes the 
prolamine storage proteins (also referred to as secalins) of rye (28). The effects of T1BL.1RS on milling and baking quality and yield parameters often depend on the wheat genetic background in which the translocation resides $(8,33)$. It is possible to remedy the deleterious effects of T1BL-1RS on end-use quality by removing the rye chromosomal portion that carries the locus responsible for rye secalins $(18,22)$. Alternatively, the incorporation of resistance genes from other sources with high molecular weight (HMW) glutenin subunits genes for better quality seems to improve end-use quality of wheat lines carrying T1BL·1RS (40).

In addition to diploid cultivated rye, triticale $(\times$ Triticosecale Wittmack) derived from crosses between Triticum spp. and $S$. cereale is an alternative source of variability from rye for wheat improvement $(25,41)$. Using a hexaploid triticale accession as a parent, the new cv. Yumai 66 was commercially released in China (T. M. Shen and X. Jia, unpublished data). This cultivar is free of any major deleterious effects on end-use quality, has outstanding yield potential, and is resistant to the fungal diseases prevalent in the various wheatgrowing regions of northern China. Several lines were developed from the cross that was used to develop Yumai 66. To facilitate the use of these wheat-triticale lines in cultivar development, an understanding of their chromosomal composition and disease reactions is required. In the present study, the wheat-triticale derivatives were characterized for their disease reactions and genomic composition.

\section{MATERIALS AND METHODS}

Plant materials. The hexaploid triticale line MZA-Lenonart BUTR was used in the cross MZA-Lenonart BUTR/Yumai 2// Lanmai 90 to develop the wheat-triticale lines Lankao 1, 3, 4, and 5. Lankao 4 was registered as Yumai 66 and has been grown commercially in several provinces in northern China since 2003 (T. M. Shen and $\mathrm{X}$. Jia, unpublished data). The susceptible checks used in the disease and the WCM tests were hard red spring wheat cvs. Rescue and Chinese Spring, soft red winter wheat cv. Chancellor, and winter wheat cv. Mingxian 169. The wheat-Thinopyrum ponticum (Podp.) Liu and Wang partial amphiploid, Agrotana (6), was used as the resistant control in assessing the reactions to WSMV and the WCM. Other entries included Lovrin 13, Key7, and Key8, which carry the T1BL.1RS translocation. TAM107, 4A7D, NOR/TAM107, and NOR/KS4200 are wheat cultivars or lines with the T1AL-1RS translocation. Wheat lines Yi80928 and 92R137 carry chromosome $6 \mathrm{~V}$ or chromosome arm 6VS from Haynaldia villosa (L.) Shchur., respectively (15). Cv. W337 carries gene Cmcl derived from Aegilops tauschii Coss. (syn. A. squarrosa L.) for resistance to the
WCM. The wheat-T. ponticum line included the WCM-resistant line 62-302228-1 (5).

Evaluation of reactions to the diseases, the WCM, and WSMV. Seedling reactions of the Lankao lines to powdery mildew, stem rust, stripe rust, WCM colonization, and WSMV were evaluated in experiments organized in a randomized complete block design with three replicates. Plots were seeded in single rows of eight plants in 6-by-17 Hillson-style Rootrainer trays (Spencer-Lemaire, Edmonton, AB, Canada) filled with Cornell mix. A bushel $\left(0.036 \mathrm{~m}^{3}\right)$ of Cornell mix consists of a blend of peat moss, vermiculite, and sand (2:2:1) along with $165 \mathrm{~g}$ of $\mathrm{CaCO}_{3}, 38 \mathrm{~g}$ of super phosphate $(0-45-0)$, $150 \mathrm{~g}$ of controlled-release fertilizer (18-612), $1 \mathrm{~g}$ of $300 \mathrm{Fe}$ Sequestrene (GoldenWest Seeds Ltd., Calgary, AB, Canada), and $2 \mathrm{~g}$ of fritted trace elements (West Can Horticultural Specialists Ltd., Calgary, AB, Canada) (2). All of the experiments were carried out twice.

Assessment of resistance to powdery mildew, stem rust, and stripe rust. Initially, the reactions of the wheat entries to powdery mildew were assessed using a mixture of the Canadian powdery mildew isolates $(15,16)$ and in a separate test that included a mixture of the Chinese isolates E11 and E15. Later, Lankao 4 (Yumai 66) was evaluated for reaction against 21 powdery mildew isolates from China following the method used by Xiang et al. (39). At the one-leaf-stage, plants from each wheat entry were dusted with the conidia of individual isolates and grown in a greenhouse at $20 \pm 2^{\circ} \mathrm{C}$ with natural light. Ten days following inoculation, plants were rated on a scale of 0 to 4 based on the powdery mildew infection types (ITs) on the first leaf as described by Si et al. (29). Resistant plants had infection types of 0 to 2 , whereas susceptible plants had infection types of 3 or 4 .

The stem rust test used a mixture (98WSR) of the stem rust virulence pathotypes TMR, RHT, QTH, RKQ, and TPM from western Canada (16). Evaluation of the reactions to stripe rust was carried out using a Canadian stripe rust race 44E14 (31). A mixture of stripe rust races composed of approximately equal proportions of CYR29, 30, 31, Hy-3, and Hy-7, which are prevalent in the major wheat-growing regions in China (36), also was used to test the reactions of the Lankao lines to stripe rust. The two- to three-leaf-stage plants were sprayed separately with spores of the stem rust and stripe rust fungus that were suspended in Soltrol mineral oil (Philips Chemical Company, Norger, TX). A light mist of water containing $2 \%$ (vol/vol) Tween-20 (polyoxyethelene sorbitan monolaureate) was applied to the plants 1 $\mathrm{h}$ after inoculation, and the plants then were incubated for 1 day in the dark in a moist plastic bag at $21^{\circ} \mathrm{C}$. For the stem rust test, plants were grown in a greenhouse at $21 \pm 3^{\circ} \mathrm{C}$ under natural light supplemented with fluorescent light at $1,000 \mu \mathrm{E} \mathrm{m} \mathrm{m}^{-2} \mathrm{~s}^{-1}$ to ensure a photoperiod of $16 \mathrm{~h}$ of light and $8 \mathrm{~h}$ of dark. Plants inoculated with stripe rust fungus were grown in a growth cabinet at $12^{\circ} \mathrm{C}$ with a photoperiod of $16 \mathrm{~h}$ of light and $8 \mathrm{~h}$ of dark. Evaluation of ITs caused by stem rust pathotypes and stripe rust races was carried out based on a 0-to-4 scale as described by Stakman et al. (30) and Volin and Sharp (35), respectively. Plants with IT $=0$ to 2 were classified as resistant and plants with IT $=3$ or 4 were regarded as susceptible.

Reactions to the WCM colonization and their effectiveness in controlling the spread of WSMV. To obtain the nonviruliferous WCM population, individual eggs of the WCM biotype that originated from southern Alberta, Canada, were transferred to the wheat-T. intermedium (Host.) Barkworth and D. R. Dewey chromosome substitution line T-Ai seedlings. The WCM population was reared on approximately $100 \mathrm{~T}-\mathrm{Ai}$ plants in four plastic pots $(10 \mathrm{~cm}$ in diameter) in a locked Conviron E-7 growth cabinet (Winnipeg, MB) set at $21^{\circ} \mathrm{C}$ with a photoperiod of $16 \mathrm{~h}$ of light and $8 \mathrm{~h}$ of dark and supplied with white fluorescent and incandescent lights at the intensity of $100 \mu \mathrm{E} \mathrm{m}^{-2} \mathrm{~s}^{-1}$ (32). The WCM population was confirmed to be free of WSMV by the absence of symptoms in WSMV-susceptible wheat cvs. Rescue and Chinese Spring when infested with WCM. Immediately after seeding, the Rootrainer trays containing the wheat entries were placed next to T-Ai plants colonized by the nonviruliferous WCM in a Conviron E-7 growth cabinet. The Rootrainer trays were rotated on a daily basis to ensure the uniform exposure to probing by the WCM. Seedlings were rated individually for rolling and trapping of the leaves starting 10 days after seeding and at 3-day intervals up to the 31 st day $(6,32)$.

Following inoculation using an artist's airbrush (Model AF-689; Paasche Air Brush Co., Harwood Heights, IL) at a pressure of $270 \mathrm{kPa}$, the plants were manually inoculated at two-leaf stage with a strain of WSMV from southern Alberta, Canada (4). The leaves of Rescue wheat plants infested by WSMV were ground in distilled water containing 2\% Carborundum (320 grit) using a mortar and pestle and diluted 1:10 (wt/vol) in distilled water to serve as inoculum. The plants were returned to a greenhouse at $25 \pm 3^{\circ} \mathrm{C}$ under natural light supplemented with fluores-

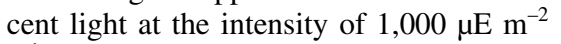
$\mathrm{s}^{-1}$ set for a photoperiod of $16 \mathrm{~h}$ of light and $8 \mathrm{~h}$ of dark. A double-antibody sandwich enzyme-linked immunosorbent assay (ELISA) kit with an alkaline phosphatase label (Agdia Inc., Elkhart, IN) was used to detect WSMV at 4 weeks after inoculation (15). Briefly, equal-size portions of the central parts of each newly developed leaf 
in a plot were bulked and $100 \mathrm{mg}$ of the bulked leaves were ground in $1.0 \mathrm{ml}$ of extraction buffer ( $2.0 \mathrm{~g}$ of bovine serum albumin, $20.0 \mathrm{~g}$ of polyvinyl pyrrolidone, and $0.2 \mathrm{~g}$ of sodium azide in $1,000 \mathrm{ml}$ of phosphate-buffered saline [PBS]-Tween 20, pH 7.4). The ELISA sample, which was composed of eight plants for each plot, was prepared by diluting $100 \mu$ of the sap with $900 \mu \mathrm{l}$ of extraction buffer. The mock-inoculated (buffer and abrasive only) Chinese Spring wheat plants and the extraction buffer were used as negative controls. The color intensities were read at 410 nm using a DYNATECH MR 5000 Microplate reader (Dynatech Laboratories, Chantilly, VA). Mean ELISA values were compared using Duncan's multiple range procedure, which was generated using the general linear model (GLM) procedure in the SAS package (version 6; SAS Institute Inc., Cary, NC). Lines with mean ELISA values that were significantly greater than those of the disease-free plants of Chinese Spring were considered positive in ELISA for WSMV.

The transmission of WSMV via viruliferous WCM was conducted by placing seedlings at the two- to three-leaf stage adjacent to Rescue wheat plants colonized by the viruliferous WCM for $24 \mathrm{~h}$ in a Conviron growth cabinet set at $21^{\circ} \mathrm{C}$ with a photoperiod of $16 \mathrm{~h}$ of light and $8 \mathrm{~h}$ of dark $\left(140 \mu \mathrm{E} \mathrm{m}^{-2} \mathrm{~s}^{-1}\right)$ (6). Then, plants were dusted with sulfur to eliminate the viruliferous WCM prior to transferring to a greenhouse with the same conditions as the previous experiment. Because the visual assessment of wheat streak mosaic (WSM) symptoms is highly correlated with ELISA absorbance readings at different growth stages following inoculation (14), symptomatological evaluation of WSM was used to assess the percentage of plants that were free of WSM symptoms on a weekly basis for 4 weeks following the initial exposure to the viruliferous WCM, which were compared using Duncan's multiple range procedure.
Sequential C-banding and genomic in situ hybridization. C-banding analysis was carried out on mitotic metaphase chromosomes from five cells per plant of three to five plants. The same slides that had undergone C-banding were immersed in a 70,95 , and $100 \%$ ethanol series for 5 min each, and genomic in situ hybridization (GISH) analysis was performed using rye genomic DNA labeled with biotin-16dUTP via nick translation (Roche Diagnostics, Mannheim, Germany) in the presence of sheared genomic DNA of Chinese Spring wheat as the blocker. The rye chromatin of the wheat-triticale lines was labeled yellow-greenish color and the wheat chromosomes were counterstained red by propidium iodide. The preparation of chromosomes, C-banding, probe labeling, and the detection of fluorescent hybridization signals were conducted as previously described $(15,16)$.

Inheritance of powdery mildew resistance in Lankao 4. To determine the number of genes controlling powdery mildew resistance, Lankao 4 (Yumai 66) was crossed as the paternal parent with the susceptible wheat cvs. Mingxian 169 and Lovrin 13 (carrying T1BL·1RS). Seedling reactions of the $F_{2}$ plants derived from each cross were tested using the powdery mildew isolate E09 as described previously $(29,39)$. A good fit of a 3:1 segregation ratio for a single dominant gene was tested using $\chi^{2}$ analysis.

Polymerase chain reaction analysis. To detect whether the powdery mildew resistance of Lankao 4 was associated with rye chromatin, polymerase chain reaction (PCR) amplification was carried out on $\mathrm{F}_{2}$ progeny of Mingxian $169 \times$ Lankao 4 that segregated in their reactions to powdery mildew isolate E09. The primers that amplified an STS marker IAG95 (IAG951: 5'-AGCAACCAAACACACCCATC-3'; IAG95-2: 5'-ATACTACGAACACACACC CC-3') were derived from the rye restriction fragment length polymorphism (RFLP) probe IAG95. The presence of rye chromosome arm 1RS was detected by the diagnostic band $1,050 \mathrm{bp}$ in length, as described by Mohler et al. (23).

\section{RESULTS}

Reaction to powdery mildew, stem rust, and stripe rust. In separate tests, inoculations with mixtures of the Canadian or Chinese powdery mildew isolates produced no susceptible symptoms or hypersensitive reactions on Lankao 1, 3, 4, and 5 (Table 1). The Lankao lines were free of symptoms when inoculated with the Canadian stripe rust race 44E14 and were resistant to the Chinese stripe rust races. These lines were resistant to a mixture of Canadian pathotypes of stem rust (98WSR). The wheat checks Rescue and Chinese Spring were susceptible to powdery mildew, stem rust, and stripe rust. Agrotana was resistant to the stem rust pathotypes but was susceptible to powdery mildew and stripe rust (Table 1).

Reaction to the WCM colonization and manual transmission of WSMV. Colonization by the nonviruliferous WCM resulted in rolling and trapping leaves much earlier on Chinese Spring and Rescue than on the Lankao lines. The symptoms of leaf trapping and rolling developed quickly; therefore, all plants of Chinese Spring and Rescue were colonized by the WCM at 22 and 25 days after seeding, respectively (Fig. 1). The date that all the plants of Lankao 1, 3, and 4 were colonized by the WCM by 31 days following seeding was later than that of the WCMsusceptible checks. A percentage of Lankao 5 plants were free of WCM colonization symptoms when all the other Lankao lines and the susceptible checks were colonized by the WCM. Agrotana did not develop any symptoms caused by WCM colonization.

When manually inoculated with WSMV, all plants of Lankao lines developed symptoms, as did Chinese Spring and Rescue, but not Agrotana. The multiplication of WSMV in these wheat-triticale hybrids

Table 1. Reaction of Lankao lines to stem rust, leaf rust, stripe rust, powdery mildew, and Wheat streak mosaic virus (WSMV)

\begin{tabular}{|c|c|c|c|c|c|c|c|}
\hline \multirow[b]{3}{*}{ Lines } & & & \multicolumn{3}{|c|}{ Infection types to the rust pathogens from ${ }^{x}$} & & \\
\hline & \multicolumn{2}{|c|}{ Powdery mildew ${ }^{\mathrm{y}}$} & \multirow{2}{*}{$\begin{array}{c}\text { Stem rust } \\
98 \mathrm{WSR}\end{array}$} & \multicolumn{2}{|c|}{ Stripe rust } & \multicolumn{2}{|c|}{ WSMV $^{\mathbf{z}}$} \\
\hline & Canada & China & & Canada & China & ELISA & Reaction \\
\hline Lankao 1 & $\mathrm{R}$ & $\mathrm{R}$ & 0,1 & 0 & 1 & $0.424 \mathrm{a}$ & $\mathrm{S}$ \\
\hline Lankao 3 & $\mathrm{R}$ & $\mathrm{R}$ & 0,1 & 0 & 2 & $0.445 \mathrm{a}$ & $\mathrm{S}$ \\
\hline Lankao 4 & $\mathrm{R}$ & $\mathrm{R}$ & 0,1 & 0 & 2 & $0.462 \mathrm{a}$ & $\mathrm{S}$ \\
\hline Lankao 5 & $\mathrm{R}$ & $\mathrm{R}$ & 0,1 & 0 & 2 & $0.396 \mathrm{a}$ & $\mathrm{S}$ \\
\hline Chinese Spring & $\mathrm{S}$ & $\mathrm{S}$ & 4 & 4 & 4 & $0.524 \mathrm{a}$ & $\mathrm{S}$ \\
\hline Rescue & S & $\ldots$ & 4 & 3,4 & $\ldots$ & $0.573 \mathrm{a}$ & S \\
\hline Agrotana & $\mathrm{S}$ & $\ldots$ & 0,2 & 4 & $\ldots$ & $0.109 \mathrm{~b}$ & $\mathrm{R}$ \\
\hline Mock-inoculated Chinese Spring & $\ldots$ & $\ldots$ & $\ldots$ & $\ldots$ & $\ldots$ & $0.075 \mathrm{~b}$ & $\ldots$ \\
\hline Extraction buffer & $\ldots$ & $\ldots$ & $\ldots$ & $\ldots$ & $\ldots$ & $0.066 \mathrm{~b}$ & $\ldots$ \\
\hline
\end{tabular}

${ }^{\mathrm{x}}$ Infection types rated based on the size of uredia and development of chlorosis or necrosis, where $0=$ no uredia or other visual symptom of infection, $1=$ small uredia surrounded by necrosis, $2=$ small to medium uredia surrounded by chlorosis or necrosis, $3=$ medium-sized uredia, and $4=$ large uredia without chlorosis or necrosis.

${ }^{\mathrm{y}} \mathrm{R}$ and $\mathrm{S}$ : resistant and susceptible reactions, respectively.

${ }^{\mathrm{z}}$ Reactions to WSMV inoculated manually were determined by enzyme-linked immunosorbent assay (ELISA) absorbance values. Mean ELISA values followed by the same letter are not significantly different based on Duncan's multiple range procedure $(P<0.05)$. 
was confirmed by ELISA. The ELISA absorbance readings for the Lankao lines were not significantly different from those of Chinese Spring and Rescue, but were significantly greater $(P<0.05)$ than those of the resistant check, Agrotana, and mock-inoculated Chinese Spring plants, the negative check (Table 1). Agrotana had ELISA values slightly higher than the mock-inoculated Chinese Spring plants, but the difference was not significant. No infectivity assay was conducted to determine whether or not the virus was present in tissue of Agrotana.

Comparison of the limitation in the spread of WSMV in Lankao lines with various sources of WCM resistance. When exposed to the viruliferous WCM, all Chinese Spring plants expressed systemic symptoms of WSM within 1 week (Table 2 ). The numbers of symptomatic wheat plants increased in Rescue, so that only a few plants escaped from WSMV infection by 4 weeks. Systemic symptoms of WSM developed more slowly in the Lankao lines than in the susceptible checks. Significant differences were noted among Lankao lines for numbers of plants without symptoms at week 1 . However, by week 4 , it was observed that 43.1 to $69.4 \%$ of plants in the Lankao lines were still free of WSM symptoms. The 1RS-carrying lines 4A7D, TAM107, NOR/TAM107, NOR/KS4200, Key7, and Key8 also reduced the incidence of WSM following exposure to the viruliferous WCM compared with the susceptible check Chinese Spring. Systemic symptoms of WSM developed slowly in the wheat- $H$. villosa 6V or 6VS lines Yi80928 and 92R137, the wheat-A. tauschii cv. $\mathrm{W} 337$, and the wheat- $T$. ponticum line 6230-2228-1. Agrotana was free of symptoms of WSM when probed by the viruliferous WCM (Table 2).
Cytological characterization of rye chromatin in the Lankao lines. Lankao $1,3,4$, and 5 had 42 chromosomes in the mitotic metaphase cells. Sequential Cbanding and GISH analysis clearly demonstrated that Lankao 4 contained a pair of the T1BL.1RS translocated chromosomes (Fig. 2A and B). Analysis of Lankao 1, 3, and 5 demonstrated similar results (data not shown). The 1RS chromosome arm was identified by its unique C-banding pattern, which displayed a strong heterochromatic band in the terminal region. The $1 \mathrm{BL}$ chromosome arm was recognized by weak bands in the terminal and near the centromeric regions (Fig. 2A). The biotinylated probe from rye genomic DNA hybridized only with the 1RS chromosome arm, which had exhibited the typical heterochromatic band following $\mathrm{C}$ banding (Fig. 2A and B).

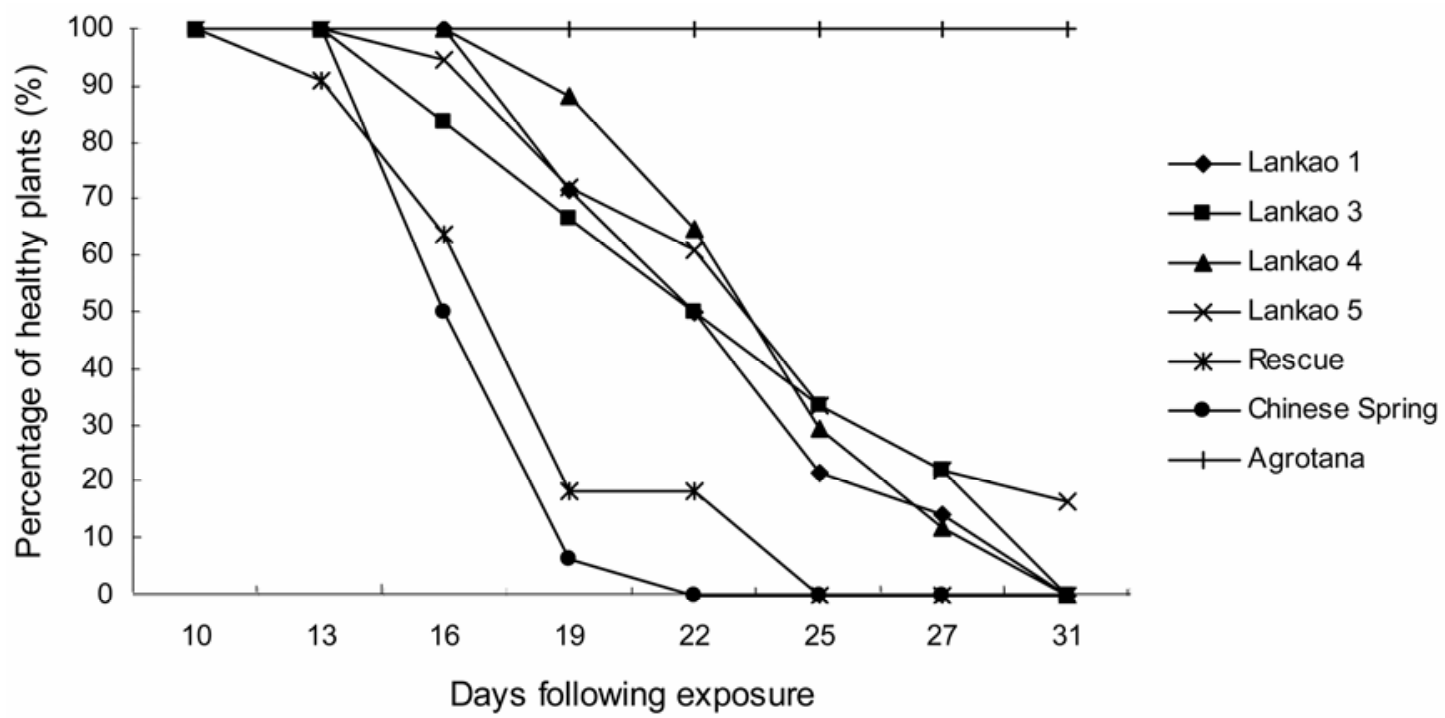

Fig. 1. Percentages of plants over time that were free of symptoms of colonization by the nonviruliferous wheat curl mite in wheat-triticale lines.

Table 2. Comparison of wheat streak mosaic (WSM) incidence transmitted by viruliferous wheat curl mite (WCM) in wheat-triticale derivatives and various sources of WCM resistance

\begin{tabular}{|c|c|c|c|c|c|}
\hline \multirow[b]{2}{*}{ Lines } & \multirow[b]{2}{*}{ Source $^{\mathrm{z}}$} & \multicolumn{4}{|c|}{ Percentage of plants without WSM symptoms following exposure to viruliferous WCM ${ }^{y}$} \\
\hline & & 1 week & 2 weeks & 3 weeks & 4 weeks \\
\hline Lankao 1 & T1BL·1RS & $85.8 \mathrm{abcd}$ & $85.8 \mathrm{abc}$ & $74.2 \mathrm{abc}$ & $61.7 \mathrm{abcd}$ \\
\hline Lankao 3 & $\mathrm{~T} 1 \mathrm{BL} \cdot 1 \mathrm{RS}$ & $97.2 \mathrm{a}$ & $79.2 \mathrm{abcd}$ & $75.0 \mathrm{abc}$ & $69.4 \mathrm{abcd}$ \\
\hline Lankao 4 & $\mathrm{~T} 1 \mathrm{BL} \cdot 1 \mathrm{RS}$ & $65.6 \mathrm{e}$ & $53.3 \mathrm{ef}$ & $47.2 \mathrm{~d}$ & $43.1 \mathrm{~d}$ \\
\hline Lankao 5 & $\mathrm{~T} 1 \mathrm{BL} \cdot 1 \mathrm{RS}$ & $90.3 \mathrm{abcd}$ & $76.4 \mathrm{bcd}$ & $59.7 \mathrm{bcd}$ & $54.2 \mathrm{bcd}$ \\
\hline 4A7D & $\mathrm{T} 1 \mathrm{AL} \cdot 1 \mathrm{RS}$ & $90.1 \mathrm{abcd}$ & 68.7 cde & $66.4 \mathrm{abcd}$ & $61.6 \mathrm{abcd}$ \\
\hline TAM107 & $\mathrm{T} 1 \mathrm{AL} \cdot 1 \mathrm{RS}$ & $90.0 \mathrm{abcd}$ & $81.5 \mathrm{abcd}$ & $74.6 \mathrm{abc}$ & $72.3 \mathrm{abc}$ \\
\hline NOR/TAM107 & $\mathrm{T} 1 \mathrm{AL} \cdot 1 \mathrm{RS}$ & $93.5 \mathrm{abc}$ & $74.3 \mathrm{bcd}$ & $69.9 \mathrm{abcd}$ & $65.0 \mathrm{abcd}$ \\
\hline NOR/KS4200 & $\mathrm{T} 1 \mathrm{AL} \cdot 1 \mathrm{RS}$ & $88.3 \mathrm{abcd}$ & $63.9 \mathrm{de}$ & $58.5 \mathrm{dc}$ & $49.0 \mathrm{~cd}$ \\
\hline Key 7 & $\mathrm{~T} 1 \mathrm{BL} \cdot 1 \mathrm{RS}$ & $74.0 \mathrm{ed}$ & $65.4 \mathrm{de}$ & $63.3 \mathrm{abcd}$ & $60.9 \mathrm{abcd}$ \\
\hline Key 8 & $\mathrm{~T} 1 \mathrm{BL} \cdot 1 \mathrm{RS}$ & 75.6 bcde & $64.5 \mathrm{de}$ & $61.8 \mathrm{bcd}$ & $55.6 \mathrm{bcd}$ \\
\hline 80928 & DS 6V(6D) & $95.1 \mathrm{a}$ & $88.0 \mathrm{abc}$ & $88.0 \mathrm{a}$ & $83.5 \mathrm{a}$ \\
\hline 92R137 & T6AL $\cdot 6 \mathrm{VS}$ & $96.7 \mathrm{a}$ & $90.6 \mathrm{ab}$ & $84.4 \mathrm{ab}$ & $78.9 \mathrm{ab}$ \\
\hline W337 & Aegilops tauschii & $93.9 \mathrm{ab}$ & $78.9 \mathrm{abcd}$ & $81.7 \mathrm{abc}$ & $75.6 \mathrm{abc}$ \\
\hline $62-30-2228-1$ & Thinopyrum ponticum & $100 \mathrm{a}$ & $97.2 \mathrm{a}$ & $77.8 \mathrm{abc}$ & $69.4 \mathrm{abcd}$ \\
\hline Rescue & Susceptible check & 81.6 abcde & $36.2 \mathrm{f}$ & $15.9 \mathrm{e}$ & $5.6 \mathrm{e}$ \\
\hline Chinese Spring & Susceptible check & $0 \mathrm{f}$ & $0 \mathrm{~g}$ & $0 \mathrm{f}$ & $0 \mathrm{e}$ \\
\hline Agrotana & T. ponticum & $100 \mathrm{a}$ & $100 \mathrm{a}$ & $100 \mathrm{a}$ & $100 \mathrm{a}$ \\
\hline
\end{tabular}

\footnotetext{
${ }^{y}$ Mean values followed by the same letter are not significantly different based on Duncan's multiple range procedure $(P<0.05)$.
}

${ }^{\mathrm{z}}$ Source of WCM resistance or susceptible check. T. ponticum $=$ resistant check. 
Inheritance of powdery mildew resistance in Lankao 4. Inoculations with 21 individual powdery mildew isolates from China showed that Lankao 4 was resistant to 14 of them that were virulent on 18 single-resistance gene and threegene combinations, including genes $P m 8$ and $P m 17$, conferred by the 1 RS chromosome arm, and $P m 7$, conferred by rye chromosome $2 \mathrm{R}$. The virulence patterns of these powdery mildew isolates on Lankao 4 were different from that on gene Pm20 conferred by rye chromosome $6 \mathrm{R}$, which was resistant to all the isolates tested. The wheat cv. Chancellor was susceptible to all the isolates tested (Table 3).
When inoculated with the powdery mildew isolate E09, which is virulent on genes $P m 8$ and Pm17, Lankao 4 developed no symptoms, but Mingxian 169 and Lovrin 13 were heavily infected. The $F_{2}$ plants derived from crosses of both Mingxian 169 $\times$ Lankao 4 and Lovrin $13 \times$ Lankao 4 segregated for resistant (R) or susceptible (S) in an R:S ratio of 3:1 (Table 4), demonstrating that a single dominant gene was responsible for the resistance of Lankao 4 to powdery mildew isolate E09. Using the STS marker IAG95, PCR analysis was carried out on 10 resistant and 10 susceptible $\mathrm{F}_{2}$ progeny plants from the cross between Mingxian 169 and Lankao 4. The diagnostic band indicating the presence of

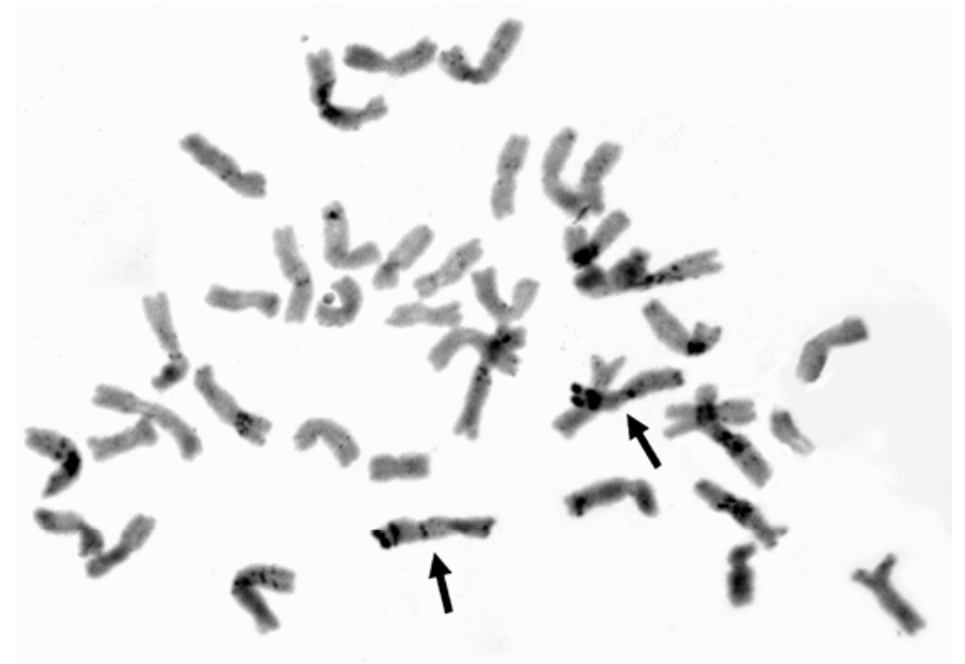

A

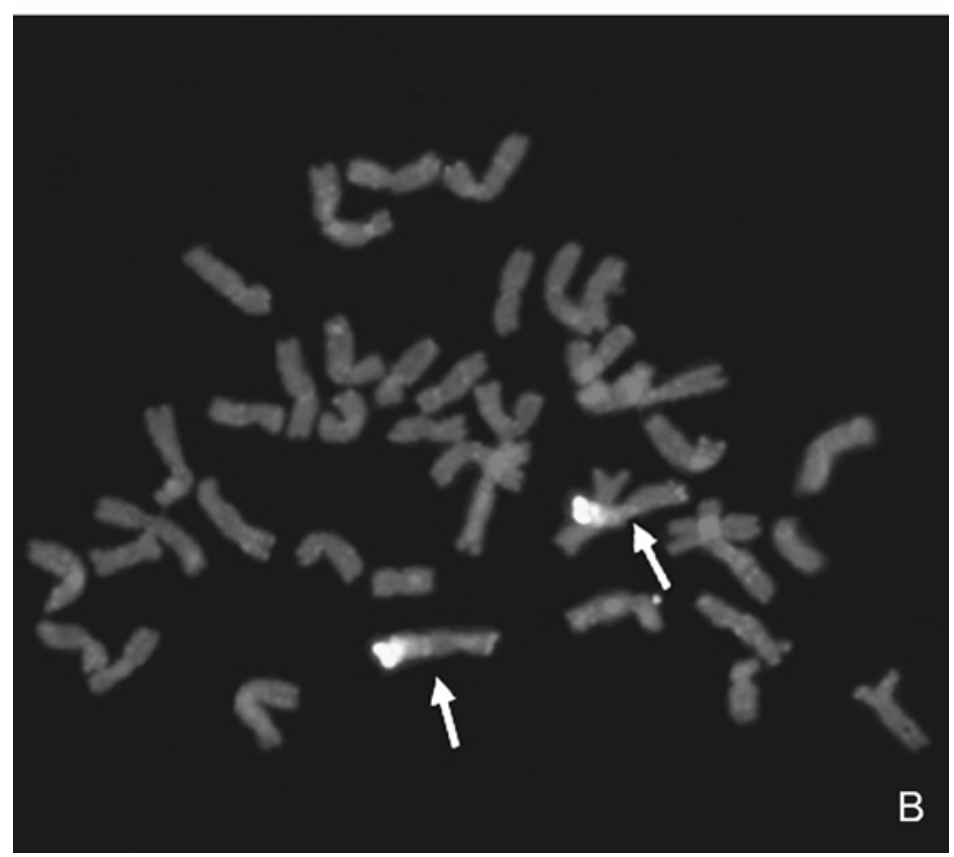

Fig. 2. C-banding and genomic in situ hybridization (GISH) analyses on mitotic metaphase chromosomes of Lankao 4. A, C-banding demonstrates an obvious heterochromatic band in the terminal and subterminal areas of chromosome arm 1RS, and bands in the centromeric and terminal regions of chromosome arm 1BL; B, GISH using labeled total genomic DNA from rye as the probe in the presence of Chinese Spring wheat DNA as the blocker reveals the strong FITC hybridization signals in the same regions that displayed the typical heterochromatic banding patterns on chromosome arm 1RS. The arrows indicate the T1BL·1RS translocated chromosomes.

rye chromatin was detected in seven resistant and eight susceptible plants. Three resistant and two susceptible plants did not have this band (data not shown).

\section{DISCUSSION}

Poor end-use quality and susceptibility to current predominant isolates of $B$. graminis and races of $P$. striiformis $\mathrm{f}$. $\mathrm{sp}$. tritici are the major concerns regarding the use of T1BL.1RS in developing wheat cultivars, although such cultivars may have high yield potential and wide adaptability $(7,8)$. Great effort has been made to remedy the detrimental effects of this translocated chromosome on wheat quality performance by removing the locus for rye secalins or introducing HMW glutenin subunits genes for better quality. The wheat-triticale hybrid Lankao 4 possesses a pair of T1BL.1RS translocated chromosomes, but has acceptable baking quality. Lankao 4 was shown to have good breadmaking properties and was tolerant to over mixing and resistant to dough making. The loaf volume of Lankao 4 was $875 \mathrm{ml}$ per $100 \mathrm{~g}$ of flour and the baking score was evaluated as $88.4 \%$. In addition, Lankao 4 was free of disease symptoms of powdery mildew in many wheat fields and had a high yield potential under favorable conditions (X. Jia, unpublished data). The present study confirmed that Lankao 4 and other Lankao lines were resistant to powdery mildew, stem rust, and stripe rust pathogens originating from China and Canada.

Genes Pm8 and Pm17 conferring resistance to powdery mildew are located on chromosome arm 1RS, which originated from the rye cvs. Petkus and Insave (21). However, these resistance genes have been overcome by virulent powdery mildew pathotypes that are prevalent in many wheat-producing areas $(1,41)$. Lankao 4 was resistant to powdery mildew isolates from different wheat-producing regions, including the isolates virulent on resistance genes conferred by the rye chromosome arm 1RS. The reactions of Lankao 4 to various powdery mildew isolates also differed from those controlled by powdery mildew resistance genes $\operatorname{Pm} 7$ and Pm20, which are located on rye chromosomes $2 \mathrm{R}$ and 6R (Table 3). The wheattriticale line Lankao 4 contains a T1BL.1RS translocation that differs in origin from those in previously described T1BL-1RS-containing cultivars. The genetic study demonstrated that this newly introduced translocated chromosome is not responsible for the resistance of Lankao 4 to powdery mildew. Segregation analysis indicates that the resistance of Lankao 4 to powdery mildew isolate E09 is controlled by a single dominant gene, which is most likely located on a wheat chromosome. Powdery mildew resistance also was detected in Lankao 1, 3, and 5, the sib lines of Lankao 4, which 
also carry T1BL·1RS translocated chromosome.

Susceptible plants will display WSM symptoms following probing by viruliferous WCM. Thus, reducing mite populations on wheat plants is an option for minimizing yield losses caused by WSMV infection. Host resistance to colonization by the WCM is genetically controlled by single dominant genes $\mathrm{Cmcl}$ derived from A. tauschii (32) and $C m c 2$ derived from $T$. ponticum (37). Similar WCM resistance in cv. TAM107 carrying the 1RS chromosome arm from Insave rye was used to limit the spread of WSM in the Great Plains region of North America (24). However, WCM resistance associated with TAM107 has been overcome (12). It was concluded that some other sources of chromosome $1 \mathrm{R}$ or $1 \mathrm{RS}$, including the popular wheat cvs. Kavkaz, Zorba, and Neuzucht, were susceptible to WCM colonization, but the T1BL·1RS translocationcarrying wheat Salmon was resistant (20). There is concern that heavy reliance on the WCM resistance from 1RS to control WSMV will result in a buildup of WCM biotypes that can colonize wheat cultivars carrying this rye chromosome arm (11).
Martin et al. (19) reported that a single mite can transfer WSMV into a wheat plant. In a previous study (15), it was demonstrated that exposure to viruliferous WCM resulted in the appearance of WSM symptoms in WCM-resistant wheat- $H$. villosa $6 \mathrm{~V}$ or $6 \mathrm{VS}$ lines. However, resistance to WCM colonization in $6 \mathrm{~V}$ or $6 \mathrm{VS}$ lines delayed the development of systemic symptoms. The development of rolling and trapping leaf symptoms caused by colonization of WCM was slower on Lankao lines than on the susceptible checks. This also was observed in other sources of mite resistance derived from rye, A. tauschii, and $T$. ponticum (Table 2). This delay in
WCM colonization of Lankao lines, as well as in previously identified sources of WCM resistance, limited the build up of WSM transmitted by viruliferous WCM even though the plants were colonized by the WCM and were susceptible to WSMV (15). Generally, WCM resistance derived from chromosome $6 \mathrm{~V}$ or $6 \mathrm{VS}$, A tauschii, and $T$. ponticum can delay the spread of WSM from viruliferous WCM (Table 2). The acquisition feeding of the WCM can be completed within $15 \mathrm{~min}$ (38). The reduction of mite infestation at an early stage gives less time for economic damage by WSM. This demonstrated that the WCM resistance does not guarantee com-

Table 4. Reaction of parents and $\mathrm{F}_{2}$ populations derived from crosses between Lankao 4 and susceptible wheat cultivars to powdery mildew isolate E09

\begin{tabular}{lrrcc}
\hline & \multicolumn{4}{c}{ Number of plants with $^{\mathbf{z}}$} \\
\cline { 2 - 5 } Parents or crosses & $\mathbf{R}$ & $\mathbf{S}$ & $\mathbf{R}: \mathbf{S}$ & $\boldsymbol{\chi}^{\mathbf{2}}$ \\
\hline Lankao 4 & 10 & 0 & $1: 0$ & $\ldots$ \\
Mingxian 169 & 0 & 10 & $0: 1$ & $\ldots$ \\
Lovrin 13 & 0 & 10 & $0: 1$ & $\ldots$ \\
Mingxian 169 $\times$ Lankao 4 & 106 & 47 & $3: 1$ & 2.67 \\
Lovrin 13 $\times$ Lankao 4 & 87 & 38 & $3: 1$ & 1.94 \\
\hline
\end{tabular}

${ }^{\mathrm{z}} \mathrm{R}$ and $\mathrm{S}=$ resistant and susceptible reactions, respectively.

Table 3. Reaction types to resistance of Lankao 4 and some cultivars or lines with known genes to 21 isolates of wheat powdery mildew from China ${ }^{\mathrm{y}}$

\begin{tabular}{|c|c|c|c|c|c|c|c|c|c|c|c|c|c|c|c|c|c|c|c|c|c|c|}
\hline $\begin{array}{l}\text { Lines or } \\
\text { cultivars }^{\mathrm{z}}\end{array}$ & $\begin{array}{c}P m \\
\text { genes }\end{array}$ & E01 & E02 & E03 & E05 & E06 & E07 & E09 & E11 & E13 & E15 & E16 & E17 & E18 & E20 & E21 & E23 & E25 & E26 & E30 & E31 & E32 \\
\hline Lankao 4 & & 0 & 0 & 0 & 0 & 0 & 0 & 0 & 0 & 0 & 0 & 4 & 0 & 4 & 4 & 4 & 0 & 0 & 4 & 0 & 4 & 3 \\
\hline Axminster/8cc & 1 & 4 & 4 & 4 & 4 & 4 & 4 & 4 & 4 & 4 & 4 & 4 & 4 & 4 & 4 & 4 & 4 & 4 & 4 & 4 & 4 & 4 \\
\hline Ulka/8cc & 2 & 0 & 0 & $1+0$ & $1+0$ & $1+0$ & 0 & 0 & 4 & 4 & 0 & 0 & 0 & 4 & 4 & 4 & $1+0$ & $1+0$ & $1+0$ & 0 & 0 & 4 \\
\hline Asosan/8cc & $3 a$ & 4 & 4 & 0 & 4 & 4 & 4 & 4 & 4 & 4 & 4 & 4 & $1+0$ & 3 & 4 & 4 & 4 & 0 & 4 & 4 & 4 & 4 \\
\hline Chul/8cc & $3 b$ & 4 & 0 & 4 & 4 & 4 & 4 & 4 & 4 & 4 & 0 & 4 & 0 & 4 & 4 & 4 & 4 & 4 & 4 & 4 & 0 & 4 \\
\hline Sonora/8cc & $3 c$ & 4 & 0 & 4 & 4 & 4 & 4 & 4 & 4 & 4 & 0 & 4 & 0 & 4 & 4 & 4 & 4 & 4 & 4 & 4 & 4 & 4 \\
\hline $\begin{array}{l}\text { Kolibri } \\
\text { Michigen }\end{array}$ & $3 d$ & $2+0$ & 0 & 0 & 4 & 4 & 4 & 4 & 4 & 4 & 0 & 4 & 0 & 4 & 4 & 4 & 4 & 4 & 4 & 4 & 4 & 4 \\
\hline Amber/8cc & $3 f$ & 4 & 4 & 4 & 4 & 4 & 4 & 4 & 4 & 4 & 4 & 4 & 4 & 3 & 4 & 4 & 4 & 4 & 4 & 4 & 4 & 4 \\
\hline Khapli/8cc & $4 a$ & 0 & 4 & $1+0$ & 0 & 0 & 0 & 0 & 0 & 0 & 4 & 4 & 4 & 4 & 4 & 4 & 0 & 0 & 4 & 0 & 3 & 0 \\
\hline Armada & $4 b$ & 0 & 0 & 0 & 0 & 3 & 0 & 0 & 0 & 0 & 0 & 4 & $1+0$ & 4 & 4 & 4 & 0 & 0 & 4 & 0 & 0 & 0 \\
\hline Hope/8cc & 5 & 4 & 4 & 4 & 4 & 4 & 4 & 4 & 4 & 4 & 4 & 4 & 4 & 4 & 4 & 4 & 4 & 4 & 4 & 4 & 4 & 4 \\
\hline Timgalen & 6 & $4+0$ & 3 & 0 & 3 & 4 & $3+0$ & 3 & 4 & $2+0$ & 0 & $2+0$ & 4 & 3 & 0 & $3+0$ & $2+0$ & 0 & $3+0$ & 1 & 0 & 3 \\
\hline CI14189 & 7 & 4 & 4 & 4 & 4 & 4 & 4 & 4 & 4 & 4 & 4 & 4 & 4 & 4 & 4 & 4 & 4 & 4 & 4 & 4 & 4 & 4 \\
\hline Kavkaz & 8 & 3 & 4 & 4 & 4 & 4 & 4 & 4 & 4 & 4 & 4 & 4 & 4 & 4 & 4 & 4 & 4 & 4 & 4 & 0 & 4 & 0 \\
\hline Wembley & 12 & 4 & 0 & 0 & 0 & $\ldots$ & 0 & 0 & 0 & 4 & 4 & 0 & $\ldots$ & 4 & 0 & 1 & 0 & 4 & $\ldots$ & 0 & 0 & 0 \\
\hline $\mathrm{R} 4 \mathrm{~A}$ & 13 & 0 & 0 & 1 & 0 & 2 & 0 & 0 & 0 & 0 & 0 & 0 & 1 & 0 & 0 & 3 & 0 & 0 & 0 & 0 & 0 & 0 \\
\hline Brigand & 16 & 0 & 0 & 0 & 0 & 0 & 0 & 0 & 0 & 0 & 0 & 0 & 0 & 0 & 0 & 0 & 0 & 0 & 0 & 0 & 0 & $1+0$ \\
\hline $\begin{array}{l}\text { Amigo } \\
\text { Synthetic } \\
\text { hexaploid wheat }\end{array}$ & 17 & 3 & 0 & 4 & 4 & 4 & 4 & 4 & 4 & 4 & 0 & 4 & 3 & 3 & 3 & 4 & 4 & 3 & 4 & 3 & 0 & 3 \\
\hline XX186 & 19 & 3 & 3 & 3 & 4 & 4 & 3 & 4 & 3 & 3 & 2 & 4 & 3 & 3 & 4 & 3 & 3 & 4 & 3 & 3 & 3 & 3 \\
\hline $\begin{array}{l}\text { PI } 583795 \\
\text { Yangmai }\end{array}$ & 20 & 0 & 0 & 0 & 0 & 0 & 0 & 0 & 0 & 0 & 0 & 0 & 0 & 0 & 0 & 0 & 0 & 0 & 0 & 0 & 0 & 0 \\
\hline 5/Sub6V & 21 & 0 & 0 & 0 & 0 & 0 & 0 & 0 & 0 & 0 & 0 & 0 & 0 & 0 & 0 & 0 & 0 & 0 & 0 & 0 & 0 & 0 \\
\hline Xiaobaidongmai & $X B D$ & 0 & 0 & 0 & 0 & $2+0$ & $1+0$ & 0 & 4 & 0 & 0 & 0 & 0 & 0 & 0 & 3 & $2+0$ & 0 & $1+0$ & 0 & 0 & 0 \\
\hline $\begin{array}{l}\text { Maris Huntsman } \\
\text { Brock }\end{array}$ & $\begin{array}{l}2+6 \\
2+\end{array}$ & 0 & 0 & 0 & 0 & 0 & 0 & 0 & 3 & 0 & 0 & 0 & 0 & 3 & $4+0$ & $3+$ & 0 & 0 & 0 & 0 & 0 & 4 \\
\hline Maris Dove & $\begin{array}{l}\text { Talent } \\
2+\end{array}$ & 0 & 0 & 0 & 0 & 0 & 0 & 0 & 4 & 4 & 0 & 0 & 0 & 4 & $3+0$ & 4 & 0 & 4 & $1+0$ & $4+0$ & $2+0$ & 4 \\
\hline & Mld & 0 & 0 & 0 & 0 & 0 & 0 & 0 & 4 & 3 & 0 & 0 & 0 & 2 & 3 & 1 & 0 & 0 & 0 & 0 & 0 & 3 \\
\hline Chancellor & $\ldots$ & 4 & 4 & 4 & 4 & 4 & 4 & 4 & 4 & 4 & 4 & 4 & 4 & 4 & 4 & 4 & 4 & 4 & 4 & 4 & 4 & 4 \\
\hline
\end{tabular}

y Reaction: $0=$ no visible colony or other symptoms of infection; 0 ; = hypersensitive reaction, white or yellow necrotic lesions with short mycelium; 1 = light mycelium with very few conidiospores; 2 = medium mycelium a few conidiospores, severity is lower than $5 \%$; $3=$ medium to strong mycelium with many conidiospores, many but separate lesions; 4; strong mycelium with many conidiospores, leaves full of lesions. More than one number indicates different infection types present in various plants.

${ }^{\mathrm{z}}$ Lines or cultivar carrying known genes for powdery mildew resistance were provided by various laboratories: $P m 1$ to $P m 8, P m 17, P m 2+6, P m 2+M l d$, and Pm2+Talent were provided by Dr. Leath of North Carolina State University; Pm21 was provided by the Institute of Plant Cytogenetic Institute, Nanjing Agricultural University, China; Pm12 and Pm16 originated from John Innes Centre, UK; Pm13 was provided by Dr. Ceoloni of Italy; and Pm19 and Pm2O were provided by Dr. Zeller of Germany. 
plete protection of wheat plants from WSMV because of random probing. Thus, the delay in WSM symptom development in mite-resistant wheat would be useful for reducing the incidence of infected plants and economic losses arising from this viral disease.

\section{ACKNOWLEDGMENTS}

We thank the National High-Technology Research and Development Program of China \#2002AA211061, the Ministry of Science and Technology of China \#2006BAD13B02, and the Matching Investment Initiative of Agriculture and Agri-Food Canada for their financial support, which was matched to funds from the Wheat Levy administered by the Western Grain Research Foundation, for providing financial support; and A. D. Kuzyk of the Lethbridge Research Centre for his technical assistance in the evaluation of disease resistance.

\section{LITERATURE CITED}

1. Bennett, F. G. A. 1984. Resistance to powdery mildew in wheat: A review of its use in agriculture and breeding programs. Plant Pathol. 33:279-300.

2. Boodley, J. W., and Sheldrake, R. 1973. Cornell peat-lite mixes for commercial plant growing. Cornell Univ. Inf. Bull. 43, Ithaca, NY.

3. Braun, H. J., Payne, T. S., Morgounov, A. I., van Ginkel, M., and Rajaram, S. 1998. The challenge: One billion tons of wheat by 2002 . Pages 33-40 in: Proc. 9th Int. Wheat Genet. Symp. A. E. Slinkard, ed. University of Saskatchewan, Saskatoon, Saskatchewan, Canada.

4. Chen, Q., Conner, R. L., Ahmad, F., Laroche, A., Fedak, G., and Thomas, J. B. 1998. Molecular characterization of the genome composition of partial amphiploids derived from Triticum aestivum $\times$ Thinopyrum ponticum and T. aestivum $\times$ Th. intermedium as sources of resistance to wheat streak mosaic virus and its vector, Aceria tosichella. Theor. Appl. Genet. 97:1-8

5. Chen, Q., Conner, R. L., Laroche, A., Fedak, G., and Thomas, J. B. 1999. Genome origins of Thinopyrum chromosomes specifying resistance to wheat streak mosaic virus and its vector, Aceria tosichella. Genome 42:289-295.

6. Conner, R. L., Thomas, J. B., and Whelan, E. D. P. 1991. Comparison of mite resistance for control of wheat streak mosaic. Crop Sci. 31:315-318.

7. Dhaliwal, A. S., Mares, D. J., and Marshall, D. R. 1987. Effect of 1B/1R chromosome translocation on milling and quality characteristics of bread wheats. Cereal Chem. 64:72-76.

8. Fenn, D., Lukow, O. M., Bushuk, W., and Depauw, R. M. 1994. Milling and baking quality of $1 \mathrm{BL} / 1 \mathrm{RS}$ translocation wheats. I. Effects of genotype and environment. Cereal Chem. 71:189-195.

9. Graybosch, R. A., Peterson, C. J., Hansen, L. E., Worral, D., Shelton, D. R., and Lukaszewski, A. J. 1993. Comparative flour quality and protein characteristics of $1 \mathrm{BL} / 1 \mathrm{RS}$ and $1 \mathrm{AL} / 1 \mathrm{RS}$ wheat-rye translocations. J. Cereal Sci. 17:95-106.

10. Harvey, T. L., and Livers, R. W. 1975. Resistance to wheat curl mite, Aceria tulipae Keifer, in rye and wheat-rye addition lines. Environ. Entomol. 4:523-526.
11. Harvey, T. L., Martin, T. J., and Seifers, D. L. 1995. Adaptation of wheat curl mite (Acari: Eriophyidae) to resistant wheat in Kansas. J. Agric. Entomol. 12:119-125.

12. Harvey, T. L., Seifers, D. L., Martin, T. J., Brown-Guedira, G., and Gill, B. S. 1999. Survival of wheat curl mites on different sources of resistance in wheat. Crop Sci. 39:18871889.

13. He, Z. H., Rajaram, S., Xin, Z. Y., and Huang, G. Z., eds. 2001. A History of Wheat Breeding in China. CIMMYT, Mexico, D.F.

14. Li, H. J., Conner, R. L., Chen, Q., Graf, R. J., Laroche, A., Ahmad, F., and Kuzyk, A. D. 2004a. Promising genetic resources for resistance to Wheat streak mosaic virus and the wheat curl mite, in wheat-Thinopyrum partial amphiploids and their derivatives. Genet. Resour. Crop Evol. 51:827-835.

15. Li, H. J., Conner, R. L., Chen, Q., Jia, X., Li, H., Graf, R. J., Laroche, A., and Kuzyk, A. D. 2002. Different reactions to the wheat curl mite and Wheat streak mosaic virus in various wheat-Haynaldia villosa $6 \mathrm{~V}$ and $6 \mathrm{VS}$ lines. Plant Dis. 86:423-428.

16. Li, H. J., Conner, R. L., McCallum, B. D., Chen, X. M., Su, H., Wen, Z. Y., Chen, Q., and Jia, X. 2004b. Resistance of Tangmai 4 wheat to powdery mildew, stem rust, leaf rust, and stripe rust and its chromosomal composition. Can. J. Plant Sci. 84:1015-1023.

17. Lukaszewski, A. J. 1990. Frequency of $1 \mathrm{RS} .1 \mathrm{AL}$ and $1 \mathrm{RS} .1 \mathrm{BL}$ translocations in United States wheats. Crop Sci. 30:1151-1153.

18. Lukaszewski, A. J. 2000. Manipulation of the 1RS.1BL translocation in wheat by induced homoeologous recombination. Crop Sci. 40:216-225.

19. Martin, T. J., Harvey, T. L., Bender, C. G., and Seifers, D. L. 1984. Control of wheat streak mosaic virus with vector resistance in wheat. Phytopathology 74:963-964.

20. Martin, T. J., Harvey, T. L., and Livers, R. W. 1976. Resistance to wheat streak mosaic virus and its vector, Aceria tulipae. Phytopathology 66:346-349.

21. McIntosh, R. A., Yamazaki, Y., Devos, K. M., Dubcovsky, J., Rogers, W. J., and Appels, R. 2003. Catalogue of gene symbols for wheat. In: Proc. 10th Int. Wheat Genet. Symp. Vol. 4. N. E. Pogna, M. Romanò, E. A. Pogna, and G. Galterio, eds. Paestum, Italy.

22. Millet, E., and Feldman, M. 1995. Deletion of the secalin gene $\mathrm{Sec}-1$ in $1 \mathrm{BL} / 1 \mathrm{RS}$ line by $\gamma-$ irradiation. Pages 851-854 in: Proc. 8th Int. Wheat Genet. Symp. Z. S. Li and Z. Y. Xin, eds. China Agricultural Scientech Press, Beijing.

23. Mohler, V., Hsam, S. L. K., Zeller, F. J., and Wenzel, G. 2001. An STS marker distinguishing the rye-derived powdery mildew resistance alleles. Plant Breed. 120:448-450.

24. Porter, K. B., Worrall, W. D., Gardenhire, J. H., Gilmore, E. C., McDaniel, M. E., and Tullen, N. A. 1987. Registration of 'TAM 107' wheat. Crop Sci. 27:818-819.

25. Rabinovich, S. V. 1998: Importance of wheatrye translocations for breeding modern cultivars of Triticum aestivum L. Euphytica 100:323-340.

26. Rajaram, S., Mann, Ch. E., Ortiz-Ferrara, G., and Mujeeb-Kazi, A. 1983. Adaptation, stability and high yield potential of certain 1B/1R CIMMYT wheats. Pages 613-621 in: Proc. 6th
Int. Wheat Genet. Symp. S. Sakamoto, ed Plant Germplasm Inst., Kyoto, Japan.

27. Reynolds, M. P., Rajaram, S., and Sayre, K. D. 1999. Physiological and genetic changes of irrigated wheat in the post-green revolution period and approaches for meeting projected global demand. Crop Sci. 39:1611-1621.

28. Shewry, P. R., Bradberry, D., Franklin, J., and White, R. P. 1985. The chromosomal locations and linkage relationships of structural genes for the prolamine storage proteins (secalins) of rye. Theor. Appl. Genet. 69:63-71.

29. Si, Q. M., Zhang X. X., Duan, X. Y., Sheng, B. Q., and Zhou, Y. L. 1992. On gene analysis and classification of powdery mildew (Erysiphe graminis f. sp. tritici) resistant wheat varieties. Acta Phytopathol. Sin. 22:349-55.

30. Stakman, E. C., Stewart, D. M., and Loegering, W. Q. 1962. Identification of physiologic races of Puccinia graminis var. tritici. USDAARS, Bull. E-167, Rev. Ed. U. S. Gov. Print Office, Washington, DC

31. Su, H., Conner, R. L., Graf, R. J., and Kuzyk, A. D. 2003. Virulence of Puccinia striiformis $\mathrm{f}$ sp. tritici, cause of stripe rust on wheat, in western Canada from 1984 to 2002. Can. J. Plant Pathol. 25:312-319.

32. Thomas, J. B., and Conner, R. L. 1986. Resistance to colonization by the wheat curl mite in Aegilops squarrosa and its inheritance after transfer to common wheat. Crop Sci. 26:527530.

33. Villareal, R. L., Bañuelos, O., Mujeeb-Kazi, A., and Rajaram, S. 1998. Agronomic performance of chromosomes 1B and T1BL.1RS near-isolines in the spring bread wheat Seri M82. Euphytica 103:195-202.

34. Villareal, R. L., Toro, E. D., Mujeeb-Kazi, A., and Rajaram, S. 1995. The 1B/1R chromosome translocation effect on yield characteristics in a Triticum aestivum L. cross. Plant Breed. 114:497-500.

35. Volin, R. B., and Sharp, E. L. 1973. Physiologic specialization and pathogen aggressive ness in stripe rust. Phytopathology 63:699703.

36. Wan, A., Zhao, Z., Chen, X., He, Z., Jin, S., Jia, Q., Yao, G., Yang, J., Wang, B., Li, G., Bi, Y., and Yuan, Z. 2004. Wheat stripe rust epidemic and virulence of Puccinia striiformis $\mathrm{f}$. sp. tritici in China in 2002. Plant Dis. 88:896904.

37. Whelan, E. D. P., and Hart, G. E. 1988. A spontaneous translocation that transfers wheat curl mite resistance from decaploid Agropyron elongatum to common wheat. Genome 30:289292.

38. Wiese, M. V. 1987. Wheat streak mosaic. Pages 80-81 in: Compendium of Wheat Diseases, 2nd ed. American Phytopathological Society Press, St. Paul, MN

39. Xiang, Q. J., Sheng, B. Q., Duan, X. Y., and Zhou, Y. L. 1996. The analysis of effective wheat powdery mildew resistance genes of some wheat breeding lines. Acta Agron. Sin. 22:741-744.

40. Zhou, Y., He, Z. H., Zhang, G. S., Xia, L. Q. Chen, X. M., Gao, Y. C., Jing, Z. B., and Yu, G. J. 2004. Utilization of $1 B L / 1 R S$ translocation in wheat breeding in China. Acta Agron. Sin. 30:531-535.

41. Zhuang, Q. S., and Li, Z. S. 1993. Present status of wheat breeding and related genetic study in China. Wheat Inf. Serv. 76:1-15. 